NBER WORKING PAPER SERIES

CAPITAL ACCUMULATION AND UNCERTAIN

LIFETIMES WITH ADVERSE SELECTION

Andrew B. Abel

Working Paper No. 1664

NATIONAL BUREAU OF ECONOMIC RESEARCH

1050 Massachusetts Avenue

Cambridge, MA 02138

July 1985

I thank Fischer Black, 01 ivier Blanchard, Peter Diamond, Benjamin Friedman, Bruce Greenwald, Nobuhiro Kiyotaki, James Poterba, Julio Rotemberg and Lawrence Summers, and the participants in seminars at Harvard University, the National Bureau of Economic Research and the University of Pennsylvania, and two anonymous referees for their helpful comments. The research reported here is part of the NBER's research programs in Economic Fluctuations and Taxation and project in Government Budget. Any opinions expressed are those of the author and not those of the National Bureau of Economic Research. 


\title{
Capital Accumulation and Uncertain \\ Lifetimes with Adverse Selection
}

\section{ABSTRACT}

This paper examines the implications of adverse selection in the private annity market for the pricing of private annuities and the consequent effects on consumption and bequest behavior. With privately known heterogeneous mortality probabilities, edverse selection causes the rate of return on private annities to be less than the actuarially fair rate based on population average mortality. However, fully funded social security system with compulsory participation can offer an implied rate of return equal to the actuarially fair rate based on population average mortality. Thos, since social security offers a higher rate of return than private annities, consumers cannot completely offset the effects of social security by transacting in the private annity market. Using an overlapping generations model with uncertain lifetimes, we demonstrate that the introduction of actuarially fair social security reduces the steady state rate of return on annities and raises the steady state levels of average bequests and average consumption of the young. The steady state national capital stock rises or falls according to the strength of the bequest motive.

\author{
Andrew Abel \\ Department of Economics \\ Littauer Center 111 \\ Harvard University \\ Cambridge, MA 02138
}


Uncertainty about an individual's date of death affects the individual's consumption and portfolio behavior as well as the bequest altimately left to the consumer's heirs. The early literature on lifetime oncertainty focused on the effects of stochastic lifetimes on individual consumption and portfolio behavior, ignoring the effects on the bequests received by subsequent generations. ${ }^{2}$ Mach recent attention has been devoted to the effects of stochastic lifetimes on bequests and the implications for the distribution of wealth and the evolution of the capital stock. Sheshinski and Weiss (1981) extended the Modigliani-Bramberg (1954) - Samuelson (1958) - Diamond (1965) overlapping generations model to include oncertain lifetimes. They assumed that all consumers are identical and, furthermore, that all consumers in a given cohort die at the same date, thereby leaving identical bequests. However, if consuers die at different dates, then they will, in general, leave bequests of different sizes. Abel (1985) and Eckstein, Eichenbaum and Peled (1985) exploited the intra-cohort variation in ex post mortality experiences to analyze the steady state distributions of bequests, consumption and wealth in models without private annuity markets and with consumers without bequest motives. ${ }^{3}$ Abel (1985) al so shows that the introduction of fully funded social security crods out steady state private wealth by more than one-for-one and that it reduces all central moments of the steady statedistribution of weal th.

The effects of social security in the presence of uncertain lifetimes have been studied by Sheshinski and Weiss (1981) and Abel (1985) in models in which there is no private annuty market. However, if a competitive annuty market were introduced into these models, social security rould then have no effect because the rate of return on private annuities rould be the same as 
the rate of return implicit in actuarially fair fully funded social security; thus consumers would exactly offset the effects of social security by adjusting their purchases of private annuities. In this paper we introduce a private market for annuities and demonstrate that with privately-known heterogenous mortality probabilities, social security does have real effects on the allocation of consuption. The reason is that adverse selection drives the rate of return on competitively supplied annities below the actuarialy fair rate of return based on the popdation average ex ante mortality probability; however, because the social security system is compulsory, it is immune to adverse selection and a fully funded system can offer a rate of return equal to the actuarialiy fair rate based on population average mortality.

Eckstein, Eichenbanm and Peled (1985b) examine the welfare-enhancing role of mandatory social secarity when the private annity market is subject to adverse selection. ${ }^{4}$ However, there are two features of their model which meke it unsuitable for onr parposes. First, because they assme that consumers have no bequest motive, the availability of annuities implies, as noted by Yaari" (1965), that consumers will hold all of their savings as annities, and hence there $i 11$ be no private intergenerational transfers in the form of bequests. Second, because the consumption good is a non-producible, nonstorable endowment, aggregate savings is zero in every period; the saving of the young is exactly offset by the dissaving of the old. In contrast, in the model presented below, the specification of the ntility function with a bequest motive introduces a nor-trivial portfolio allocation problem and leads to intergenerational transfers in the form of bequests. Secondly, in the model below, the consumption good can be invested at a rate of return $R$ so that agregate saving need not be zero. Thus, this model can be used to analyze 
the effects of social security on capital accundation.

In section $I$, we examine the optimal consumpion and portfolio behavior of an individual consmer, taking as given the rate of return on private annuities and the consumer's inheritance received from his parent. Using the derived demands for private annuties by consmers with different mortality probabilities, we study, in section II, the determination of the rate of return on private annities. In section III, we analyze the steady state effects of introducing actuarially fair fully funded social security. Te show that the introduction of fully funded social security leads to an increase in the steady state consuption of young consumer, an increase in the steady state level of bequests, and to a reduction in the rate of return on private annuities. Finally, we show that depending on strength of the bequest motive, an actuarially fair increase in social security taxes will crowd out private capital by greater than or less than one-for-one.

\section{Consumption and Portfolio Behavior of an Individual}

Consider a consmer who may live either one period (with probability p>0) or two periods (with probability 1-p>0). Let I be the initisl wealth held by the consumer at the beginging of his life. (The determination of I will be discussed below.) During the first period of life the consmer earns a fired labor income $Y$, pays a social security tax $T$, and consumes an amount c 1 . At the end of the first period, the consumer chooses a portfolio of annuities and riskless bonds. Let $Q$ be the amount of annuities held in the portfolio; the remainder of the portfolio, $I+Y-T-c_{1}-Q$, is held in the form of riskless bonds. A one dollar annuity pays A dollars to the consmer in the following 
period if he survives; if the consumer dies young, the annuity pays nothing to his heir. A one dollar riskless bond yields dollars in the following period to the consumer, if he survives, or to his heir, if the consumer dies young. As shown in section II, A>R in a competitive annuity market.

At the beginning of the second period, the consumer gives birth to an heir and then the uncertainty about the length of the consumers 1 ife is resolved. If the consumer dies at the beginning of the second period, his heir receives a bequest, $B^{D}$, consisting of the consumer's riskless bonds with accrued interest,

$$
B^{D}=\left(I+Y-T-c_{1}-Q\right) R
$$

If the consumer survives to the end of the second period, he receives a social security payment $S$, consumes an amonnt $c_{2}$, and gives the remainder of his wealth, $B^{s}$, to his heir. Since all uncertainty is resolved at the beginning of the second period, the consumer who lives for two periods bows at the beginning of the second period that he will leave a bequest of $B^{5}$ where

$$
B^{S}=\left(I+Y-T-c_{1}-Q\right) R+Q A+S-c_{2}
$$

We assume that the consumer who survives gives his heir the bequest $B^{s}$ at the beginning of the second period. Thus, regardless of whether the consumer lives one period or two periods, the intergenerational transfer from the consumer to his heir takes place at the beginning of the second period i.e., at the beginning of the first period of the heir's life.

Let the consumer's ntility function be

$$
\mathrm{U}\left(\mathrm{c}_{1}\right)+\mathrm{p} \delta \mathrm{V}\left(\mathrm{B}^{\mathrm{D}}\right)+(1-\mathrm{p}) \delta \mathrm{U}\left(\mathrm{c}_{2}\right)+(1-\mathrm{p}) \delta \mathrm{V}\left(\mathrm{B}^{\mathrm{S}}\right)
$$

where $\delta(0<\delta \leq 1)$ is the one-period discont factor, $U()$ is a strictly concave 
utility index of the consumer's own consumption and $V()$ is a strictly concave inder of utility derived from leaving bequest. The utility function in (1) is simply the expected value of utility, where the only stochastic element is the consurer's date of death.5

The consumer maximizes the atility function in (3) subject to his lifetime budget constraint. The lifetime budget constraint is obtained by first substituting (1) into (2) to obtain

$$
B^{S}=B^{D}+Q A+S-C_{2}
$$

Then combining (1) and (4) to eliminate $Q$ yields

$$
B^{S}=A(I+Y-T)+S-A c_{1}-c_{2}-\left(\frac{A-R}{R}\right) B^{D}
$$

Substituting the lifetime budget constraint (5) into the utility function and differentiating with respect to $c_{1}, c_{2}$, and $B$, respectively, yields

$$
\begin{gathered}
U^{\prime}\left(c_{1}\right)=(1-p) \delta A V^{\prime}\left(B^{s}\right) \\
U^{\prime}\left(c_{2}\right)=V^{\prime}\left(B^{s}\right) \\
p V^{\prime}\left(B^{D}\right)=(1-p) \frac{A-R}{R} V^{\prime}\left(B^{s}\right)
\end{gathered}
$$

Annuties are said to be actuarially fair if the expected rate of retarn on an annuity, (1-p)A, is equal to the rate of return on riskless bonds, R. Note that actuarial fairness implies that $\frac{A-R}{R}=\frac{p}{1-p}$ so that from (6c) we obtain $V^{\prime}\left(B^{D}\right)=V^{\prime}\left(B^{S}\right)$ and hence $B^{D}=B^{S}$. Furthermore, since $B^{D}=B^{S}$, it follows from (4) that $c_{2}=Q A+S .^{6}$ Thus, if the rate of return on private annuities is actuarially fair, the consumer's portfolio consists of: riskless bonds which will be given to his heir as a bequest; and (2) annuities Which, along with the social security payment $S$, will be used to provide for second-period consumption. 
If the expected rate of return on anuities is smaller than the riskless rate of return $B$, i.e.. $A<\frac{R}{1-p}$ then it follows from $(6 c)$ that $V^{\prime}\left(B^{D}\right)<V^{\prime}\left(B^{S}\right)$ so that $B^{D}>B^{S}$ and (from (4)) $c_{2}>Q A+S$. In this case the consmer does not ase annities to provide for all of second-period consumption; some of second-period consumption is provided for by riskless bonds wich have a higher expected rate of return than annuities. 7

In order to obtain explicit solutions for the optimal levels of consumtion and bequests, we as sume that $U(c)=\frac{c-\sigma_{-1}}{1-\sigma}$ and $V(B)=\lambda^{1-\sigma_{-1}} \frac{1-\sigma}{1-a s}$ in Hakansson (1969), Fischer (1973) and Richard (1975), where $\lambda \geq 0$ indicates the strength of the bequest motive and $\sigma>0$. Therefore the atility function in (3) is homothetic, and the income expansion path for $c_{1}, c_{2}, B^{D}$ and $B$ is a ray through the origin. The optimal value of each of these variables, as well as the demand for contingent second-period income $Q A+S$, is proportional to the. expected present value of lifetime resources $I+Y-T+A^{-1} S$. It is shown in Appendix A that

$$
c_{1}(p, A)=\phi(p, A)\left(I+Y-T+A^{-1} S\right)
$$

where

$$
0<\phi(p, A)<1
$$

and

$$
Q(p, A)+A^{-1} S=q_{1}(p, A)\left(I+Y-T+A^{-1} S\right)
$$

where

$$
q_{1}(p, A)<1 .
$$

Explicit expressions for $b(p, A)$ and $q_{1}(p, A)$ are presented in Appendix A. It can be shown that $\partial q_{1} / \partial p<0$. Also, $q_{1}(p, A)$ will be positive if and only if 


$$
A>\frac{R}{1-p}\left[(1-p)+p\left(\frac{\lambda^{\frac{1}{\sigma}}}{1+\lambda^{\frac{1}{\sigma}}}\right)^{\sigma}\right] \geq \mathbf{R}
$$

If $S=0$, then (9) is necessary and sufficient for a positive demand for annuities. With actuarially fair annuties $\left(A=\frac{R}{1-p}\right),(9)$ is satisfied.

It is convenient to rewite (8), the demand for private annuities as

$$
Q(p, A)=q_{1}(p, A)(I+Y-T)-q_{2}(p, A) S
$$

Where

$$
q_{2}(p, A)=\left[1-q_{1}(p, A)\right] A^{-1}
$$

Since $q_{1}(p, A)\left\langle 1\right.$ and $\partial q_{1} / \partial p<0$, it follows from $(10 b)$ that $q_{2}(p, A)>0$ and that $\frac{\partial q_{2}}{\partial p}>0$. Therefore, if $I+Y-T>0$ and $S \geq 0$, then

$$
\frac{\partial Q}{\partial p}<0
$$

\section{Equilibrinm in the Private Annuity Market}

Suppose that consumers are characterized by different probabilities, p, of dying young. We will refer to a consumer with a probability $p$ of dying young as a type p consumer. Except for the difference in $p$, all consumers have identical otility functions. Let $H(p)$ be the fraction of young consurers with probability of dying young less than or equal to $p$. The support of the distribution $B(p)$ is $\left[p^{L}, p^{H}\right]$, where $0<p^{L}<p^{H}<1$. We restrict the range of values of $p$ in the population by assuning that that

$$
\frac{\lambda}{\left(1-p^{H}\right)\left(1+\lambda^{\frac{1}{\sigma}}\right)^{\sigma}+p^{H} \lambda} p^{H}<p^{L}<p^{H}
$$

The effect of this assumption is to guarantee that condition (9) is satisfied so that if $S \geq 0$ is sufficiently small, then all consumers will have a positive 
demand for anuities. 8

A consumer's probability of dying young, $p$, is independent of the $p$ of his parent. Moreover, we assume that each individual knows his own value of $p$ bat that annuity companies and the government are unable to determine an individual consumer's $p$. We assume that there is no aggregate uncertainty: a fraction p of each cohort of type p consumers will die goung. Finally, we assume that annity companies cannot determine whether an individual consumer holds annuities from other insurance companies. The effect of this assumption is that the equilibrium in the annuty market will be a pooling equilibrium rather than a separating equilibrium. 9

Assuming that annuity companies are risk-neutral and perfectly competitive, the expected profits of annuity companies must be equal to zero. Let $M(p, A)$ be the expected profit per dollar of annuity with rate of return $A$ issued to a type p consumer. Therefore

$$
M(p, A)=R-(1-p) A
$$

so that $\frac{\partial M}{\partial p}=A>0$. It is obvious that the equilibrium rate of return on annuities, $A$, must 1 ie between $\frac{R}{1-p^{L}}$ and $\frac{R}{1-p^{H}}$ : if $A$ were less than $\frac{R}{1-p^{L}}$ then an annity company could offer a rate higher than $A$ and profitably attract all buyers of annuities; if $A$ were greater than $\frac{R}{1-p}$, then annuity companies would suffer expected losses on all annities sold.

We will now show that the competitive rate of retarn on annuties, A, must be less than $\bar{A}$, the actuarially fair rate based on popalation average mortality, where $\bar{A} \equiv \frac{R}{1-\bar{p}}$ and $\bar{p} \equiv \int_{p}^{L} p d H(p)$ is the popalation average probabil- 
ity of dying young. First, we state the following we11-known lemma.

LEMMA. Suppose that $f(p) \leq 0$ as $p \leq p *$ and that $\int_{f}^{B} f(p) d H(p)=0$. If $g(p)$ is strictly increasing, then $\int_{\int}^{B} f(p) g(p) d H(p) \geq 0$, with strict inequality if $\mathbf{p}^{\mathbf{L}}$

$d H(p)$ is not degenerate. 10

Let $\pi\left(A ; I^{*}+Y-T, S\right)$ be the expected profit of the annuity industry if the private annuty rate of return is A. Observe that

$$
\pi\left(A ; I^{*}+Y-T, S\right)=\int_{p^{L}}^{p^{H}} \cdot M(p, A) Q *(p, A) d H(p)
$$

where $Q *(p, A)=q_{1}(p, A)(I *+Y-T)-q_{2}(p, A) S$ is average annuity demand of type $p$ consumers and $I^{*}$ is the average inheritance received at birth. Dsing the relation $M(p, A)=M(p, \bar{A})+(1-p)(\bar{A}-A)$ which follows from $(13)$, we can rewrite (14) as

$$
\pi(A ; I *+Y-T, S)=\int_{p^{L}}^{p} M(p, \bar{A}) Q^{*}(p, A) d H(p)+(\bar{A}-A)^{p} \int_{p^{L}}^{H}(1-p) Q *(p, A) d H(p)
$$

Since $\int_{p^{L}}^{P} M(p, \bar{A}) d H(p)=0($ from (13) and the definition of $\bar{A})$ and since $\frac{\partial Q^{*}}{\partial p}<0$ (from (11)), the lemma implies that the first integral in (15) is negative. Since (for S sufficiently smal1) the second integral in (15) is positive, it follows that if $A \geq \bar{A}$, then $\pi(A)<0$. The result that $\pi(\bar{A})<0$ is, of course, a consequence of adverse selection. Therefore, the equilibrium rate of return A must 1 ie in the open interval $\left(\frac{R}{1-p}, \frac{R}{1-\bar{p}}\right)$.

The equilibrium rate of return on private annities, $A$, must be root of the equation $\pi(A)=0$. Since $\frac{R}{1-p l}\left\langle A\left\langle\frac{R}{1-\bar{p}}, \pi\left(\frac{R}{1-p}\right)>0>\pi\left(\frac{R}{1-\bar{p}}\right)\right.\right.$ and $\pi(A)$ 
is a continuous function of $A$, there is at least one root of $\pi(A)=0$ between $\frac{R}{1-p^{L}}$ and $\frac{R}{1-\bar{p}}$ for which $\pi^{\prime}(A) \leq 0$. We demonstrate in Appendix $B$ that in the case of logarithmic atility $(\sigma=1), \pi(A)$ is strictly concave for $A>R$ and thas there is anique root $A$ of $\pi(A)=0$ in $\left(\frac{R}{1-p^{L}}, \frac{R}{1-\bar{p}}\right)$ and $\pi^{\prime}(A)<0.11$

The equilibrium annity rate of return, $A$, can be expressed as a function of $I^{*}+Y-T$ and $S$. Observe from (10a) that $Q *(p, A)$ is a linearly homogeneous function of $I^{*}+Y-T$ and $S$. Therefore, from (14), $\pi\left(A ; I^{*}+Y^{-T}, S\right)$ also linearly homogeneous in $I^{*}+Y-T$ and $S$, so that if $A$ satisfies $\pi(A ; I *+Y-T, S)=0$, it also satisfies $\pi\left(A ; \beta\left(I^{*}+Y-T\right), \beta S\right)=0$ for any $\beta>0$. Hence $\AA$ can be written as

$$
\AA=\AA(I *+Y-T, S)
$$

where $\AA(\ldots)$ is homogeneous of degree zero.

To demonstrate that $\partial \AA / \partial S<0$, recall from $(10 a)$ that an increase in social security benefits leads type p consumers to reduce their demand for private annuities by $q_{2}(p, A)$. Since $\frac{\partial q_{2}}{\partial p}>0$, consumers with high $p$ reduce their annity demands by more than low p consuers. Furthermore, since high $p$ consumers begin with a lower demand for annuities than low $p$ consmers, the percentage reduction in annuty demand is greatest for high p consumers. Now, since it is the annities sold to the high p consumers on which annuity companies expect positive profits, this shift in the composition of annity holders aw 8 from the profitable (high p) consmers leads to a reduction in expected profits. In order to restore zero expected profits, the equilibrium rate of return must fall (since $\left.\pi^{\prime}(\AA)<0\right)$. Thus, the partial derivatives of $A(I * I-T, S)$ are

$$
\frac{\partial \hat{A}}{\partial S}<0
$$




$$
\frac{\partial A}{\partial(I *+Y-T)}=\frac{-S}{T^{*}+Y-T} \text { aA } \geq 0 \text { as } S \geq 0
$$

where (17a) follows from applying Euler's Theorem to $\AA(\ldots)$ which is homogeneons of degree zero.

\section{The Steady State Effects of Changes in Social Secrity}

Let $B_{t}^{*}(p)$ denote the actual ex post bequests (per capita) left by the group of type $p$ consumers born at the beginning of period $t$. Letting $B_{t}^{D}(p)$ denote the bequests (per capita) of the consumers who died young and ${ }_{t} S_{(p)}$ denote the bequests (per capita) of the consumers who survived two periods, and recalling that a fraction $p$ of type $p$ consumers dies young, we obtain

$$
B_{t}^{*}(p)=p B_{t}^{D}(p)+(1-p) B_{t}^{S}(p)
$$

The homotheticity of preferences implies that $B_{t}^{D}(p)$ and $B_{t}^{S}(p)$ are each proportional to the expected present value of lifetime income so that (18) may be rewritten as

$$
B_{t}^{*}(p)=\theta\left(p, A_{t}\right)\left[I_{t}^{*}+Y-T+A_{t}^{-1} S\right]
$$

where $I_{t}^{*}$ is the initial bequest (per capita) received at birth; $A_{t}$ is the rate of retarn on annities purchased at the end of period $t$ (and which pay of $f$ in period $t+1)$. An expression for $\theta\left(p, A_{t}\right)$ is given in Appendix $A$. We will assume that $0<\theta\left(p, A_{t}\right)<1$ for $p^{L} \leq p \leq p^{B} .12$

Define $B_{t}^{*} \equiv \int_{p}^{\mathrm{p}} B_{t}^{*}(p) d H(p)$ to be the average bequest left by members of the generation born at time $t$. It follows from (19) that

$$
B_{t}^{*}=\bar{\theta}\left(A_{t}\right)\left[I_{t}^{*}+Y-T+A_{t}^{-1} S\right]
$$

where 


$$
\bar{\theta}\left(A_{\tau}\right)=\int_{p}^{L} \theta\left(p, A_{t}\right) d H(p)
$$

In the steady state $B_{t}^{*}=I_{t}^{*}$ so that (dropping the time subscript) (20a) may be rewritten as

$$
B *=\frac{\bar{\theta}(A)}{1-\bar{\theta}(A)}\left(Y-T+A^{-1} S\right)
$$

We as sume that $0<\bar{\theta}(A)<1.13$

A fully funded social security system operates by collecting $T$ from each young consumer and investing the proceds in riskless capital earning a gross rate of return $R$. In the following period the social security tax cum interest, RT, is divided equally among the surviving consumers. Since a fraction $1-\bar{p}$ of the consumers survives to the second period, the payment $S$ received by each surviving consumer is

$$
\mathbf{S}=\overline{\mathrm{A}} \mathbf{T}
$$

Where recall that $\bar{A}$ is defined as $R /(1-\bar{p})$. Equation (22) shows that the marginal rate of return implicit in the social security system, $\frac{d S}{d T}$, is $\bar{A}$ which, as we have shown in Section II, is greater than A, the equilibrium rate of return on private annuties. Therefore, an actuarially fair increase in social security taxes and benefits increases the expected present value 1 ifetime income $I+Y-T+A^{-1} S$, for a given level of inherited wealth $I$.

We will confine our attention to small increase in $S$ and $T$ starting from an initial steady state in which $S=0$. It follows immediately from (17b) that $\frac{\partial A}{\partial(I+Y-T)} \mid S=0=0$ so that

$$
\left.\frac{\mathrm{dA}}{\mathrm{dS}}\right|_{\mathrm{S}=0}=\frac{\partial \mathrm{A}}{\partial \mathrm{S}}<0
$$

Thus, an increase in fully funded social security reduces the steady state 
rate of return on anuities.

Henceforth, we assume that $\sigma=1$ (logarithmic utility) so that, as shown in Appendix $D, \bar{\theta}^{\prime}(A) \leq 0$. The state state level of bequests is found by substituting (22) into (21) to obtain

$$
B *=\frac{\bar{\theta}(A)}{1-\bar{\theta}(A)}\left(Y+\left(A^{-1}-\bar{A}^{-1}\right) S\right)
$$

Differentiating (24) with respect to s yields

$$
\left.\frac{d B^{*}}{d S}\right|_{S=0}=\frac{\bar{\theta}(A)}{1-\bar{\theta}(A)}\left[A^{-1}-\bar{A}^{-1}\right]+\left.\frac{\bar{\theta}^{\prime}(A)}{(1-\bar{\theta}(A))^{2}} Y \quad Y \frac{d A}{d S}\right|_{S=0}>0
$$

where the inequality follows from $A<\bar{A}, \bar{\theta}^{\prime}(A) \leq 0$ and (23). The increase in $B^{*}$ occurs for two reasons. First, since social security pays a higher rate of return than private annities, the introduction of social security raises (by $\left.\left(A^{-1}-\bar{A}^{-1}\right) d S\right)$ the expected present value of 1 ifetime resources for a given initial wealth. Second, the $f a 11$ in $A$ canses the share of lifetime resources passed on as bequests, $\bar{\theta}(A)$, to rise. Therefore, the factor $\frac{\bar{\theta}(A)}{1-\bar{\theta}(A)}$ in (21) I ises.

Next we examine the effect of social security on the steady state level of average consumption of the young, $c_{1}^{*}$, where

$$
c_{1}^{*}=\bar{b}(\mathrm{~A})\left(\mathrm{B}^{*}+\mathrm{Y}-\mathrm{T}+\mathrm{A}^{-1} \mathrm{~S}\right)
$$

where

$$
\sigma(A) \equiv \int_{p}^{p} b(p, A) d H(p)<1
$$


With logarithmic atility, $\bar{Z}(A)=\bar{\zeta}$ is invariant to A. Therefore, the effect of social security on $c_{1}^{*}$ is proportional to the effect on $B^{*}+Y-T+A^{-1} S$ which increases as a result of three effects: (1) B rises as shown in (25); (2) since the gross retarn on social security, $S / T$, exceeds $A$, it follows that $-T+A^{-1} S$ rises for given $A$; and (3) $A$ falls as shown in (23) so that, $A^{-1} S$, the present value of the social security payment, rises. Therefore, the expected present value of lifetime resources rises and a fortiori the average consumption of young consumers al so rises. ${ }^{14}$

The steady state private capital stock at the end of a period is equal to the saving of young consumers $B^{*}+Y-T-c_{1}^{*}$. In a fully funded social security system, the end-of-period capital stock held by the government is $T$. The steady state national capital stock $K^{*}$ is the sum of private capital and government capital

$$
\mathrm{K} *=\mathrm{B} *+\mathrm{Y}-\mathrm{c}_{1} *
$$

Substituting (24) and (26a) into (27) yields

$$
K *=\mathbf{Y}+\frac{\bar{\theta}(A)-\overline{\underline{B}}}{1-\bar{\theta}(\mathrm{A})}\left[\mathrm{Y}+\left(\mathrm{A}^{-1}-\overline{\mathrm{A}}^{-1}\right) \mathrm{S}\right]
$$

Differentiating (28) with respect to $S$, we obtain

$$
\left.\frac{d K}{d S}\right|_{S=0}=Y \frac{1-\bar{\phi}}{(1-\bar{\theta}(A))^{2}} \quad \bar{\theta} \cdot(A) \frac{d A}{d S} I_{S=0}+\frac{\bar{\theta}(A)-\bar{\phi}}{1-\bar{\theta}(A)}\left(A^{-1}-\bar{A}^{-1}\right)
$$

Since $\bar{\theta}^{\prime}(A) \leq 0$ it follows from (23) that the first term on the right hand side of (29) is positive. Since $A^{-1}>\bar{A}^{-1}$ the second term on the right hand side of (29) Will be positive if $\bar{b}\langle\bar{\theta}(A)<1$. In this case, the right hand side of (29) is unambiguously positive so that the introduction of fully funded social 
$-15-$

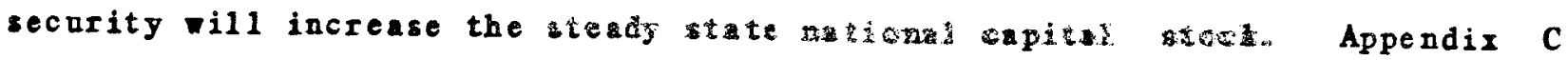
provides conditions under which $\bar{C}(\bar{G}(A)<1$. Intuitively, the bequest motive as measured by $\lambda$ most be sufficiently strong so that larges share of lifetime resources is devoted to bequest than to first-pexiod consumption.

In the case in which $\bar{\theta}<\bar{\phi}$, the first term the right has ed side of (29) remains positive, but the second term is negative. Observe that if $\lambda=0$, then $\bar{\theta}(A) \equiv \bar{\theta}^{\prime}(A) \equiv 0$ and the first term ox the right hand side dz eng becomes zero. Thus, if the bequest motive is sufficiently weak, then an increase in fully funded social security will reduce the total notional capital stook in the steady state. Thus we have showa

$$
\begin{aligned}
& \left.\frac{\mathrm{dK} *}{\mathrm{dS}}\right|_{S=0}>0 \text { if } \lambda \text { is } \bar{\delta}(A)<\bar{\theta}(A)<1
\end{aligned}
$$




\section{Conclusion}

In this paper we have developed an overlapping generations model based on individar atility maximization subject to uncertainty about the date of death. Fe used this model to examine the dynamic behavior of consuption and bequests in an economy with consumers who have different probabilities of dying. Even though there are markets in annuities and in riskless bonds, corsumers are unable to of set the introduction of actuarially fair social secarity. The reason is that adverse selection in the private annuity market leads to a rate of return on private annuities which is lower than the rate of return implicit in compulsory social security.

The introduction of actuarially fair social security raises the steady state average levels of bequests and first-period consuption; it reduces the steady state rate of return on private annuities. If the bequest motive is sufficiently weak, then an increase in fully funded social security benefits reduces private wealth by more than one-for-one. With a sufficientiy strong bequest motive, an increase in social security taxes crowds out private wealth by less than one-for-one. 


\section{Footnotes}

1. The seminal work in this area is Yaari (1965), which provided the framework for later work by Hakansson (1969), Fischer (1973), Richard (1975), Levhari and Mirman (1977), Barro and Friedman (1977) and Kotlikoff and Spivak (1981).

2. Kotlikoff and Spivak (1981) examine the role of the family in providing an (incomplete) annities market but stop short of a ful1-scale overlapping generations model in which the intra-cohort distribution of bequests is determined endogenously.

3. See Kotlikoff, Shoven and Spivak (1983) and Karni and Zilcha (1984) for interesting extensions of the overlapping generations mode1 in which consumers within a cohort have different ex post mortality experiences.

4. Their analysis is more general than an analysis of annity markets which are based on 1 ifetime uncertainty; it applies more generally to mandatory insurance as a partial remedy for adverse selection in insurance markets. In particular, Eckstein, Eichenbaum and Peled pay careful attention to various concepts of equilibrium.

5. We follow Yaari (1965), Hakansson (1969), Fischer (1973) and Richard (1975) in specifying atility as a function of the size of the bequest left to one's heir. An alternative formulation which also gives rise to a bequest motive is to specify utility as a function of one's heir's otility as in Barro (1974) and Drazen (1978).

The specification of atility as a fuction of the size of the bequest left to one's heir as chosen for tractability. The substantive results of this paper do not depend on choosing this specification rather than the specification suggested by Barro (1974). In particular, the fact that social security affects consumption and capital accumalation depends, not on the particular specification of the bequest motive, but rather on the fact that adverse selection drives a wedge between the rates of return on social security and on private annities. In the absence of adverse selection, fully funded social security wonld not affect consumption regardless of whether the bequest motive is specified as in this paper or as in Barro (1974).

6. Sheshinski and Teiss (1981) have derived similar result in model which is similar in spirit, but different in detail from the model in this paper.

7. If $A>\frac{R}{1-p}$, then all of the results in this paragraph are reversed.

8. To derive this implication, we observe that (as will be argued below) competition in the annity market will prevent the rate of return A from being less than $\frac{R}{1-p}$. Let $N(p, A)$ be the nomerator of $q_{1}(p, A)$ in $(A-8 b)$, i.e., $N(p, A)=1+\lambda^{\frac{1}{\sigma}}\left[1-\left(\frac{1-p}{p}\right)^{\frac{-1}{\sigma}}\left(\frac{A-R}{R}\right)^{\frac{-1}{\sigma}}\right]$. Observe that $\partial N / \partial p<0$ and 
$\partial N / \partial A>0$. Next observe that $N\left(p^{H}, \frac{R}{1-p}\right)$ will be positive if and only if $\frac{p^{L}}{1-p}>\left(\frac{\lambda^{\frac{1}{\sigma}}}{\frac{1}{\sigma}^{\sigma}}\right)^{\sigma}\left(\frac{p}{1-\lambda^{B}}\right)$ which will be true if and only if equation

holds. Note that the term on the left of the first inequality in (12) is less than $p^{H}$ since this term can be written as

$\left\{1+\left(1-p^{H}\right)\left[\left(1+\lambda^{\frac{-1}{\sigma}}\right)^{\sigma}-1\right]\right\}^{-1} p^{H}$. Therefore, given $p^{H}, \lambda$, and $\sigma$, the set of possible values for $p^{L}$ is not empty.

Since we have shown that (12). implies that $N\left(p^{B}, \frac{R}{1-p}\right)>0$, it follows from $\partial N / \partial p\left\langle 0\right.$ and $\partial N / \partial A>0$ that $N(p, A)>0$ for $p \leq p$ and $A \geq \frac{R}{1-p}$ if (12) holds. Therefore, equation (12) implies that $q_{1}(p, A)>0$, since the denominator of the right hand side of $(A-8 b)$ is positive.

9. The Rothschild and Stiglitz (1976) demonstration that there cannot be a pooling equilibrinm depends on their assumption "that customers can buy only one insurance contract". As they point out themselves, "this is an objectionable assumption" (p. 632). The appropriate equilibrium concept in the presence of monitoring of purchases from other companies still requires further research. The equilibrinm described in this paper has some desirable characteristics and is suitable for our purposes.

10. The proof of this lemma is

$$
\begin{aligned}
& \int_{p^{L}}^{p^{H}} f(p) g(p) d H(p)=\int_{p^{L}}^{p^{*}} f(p) g(p) d H(p)+\int_{p^{*}}^{p^{H}} f(p) g(p) d H(p) \geq \\
& g\left(p^{*}\right)\left[\int_{p^{L}}^{p^{*}} f(p) d H(p)+\int_{p^{*}}^{H} f(p) d H(p)\right]=0 .
\end{aligned}
$$

11. More generally, when $\sigma$ is not equal to one $e_{R}$ we have not ruled out multiple roots of $\pi(A)=0$ in the interval $\left(\frac{R}{L}, \frac{R}{-}\right)$. Nonetheless, we can role out as possible equilibria those roots for which $\pi^{\prime}(A)>0$ by observing that if such an were the prevailing rate of return on private annities, a firm could offer a slightly higher rate of return and profitably attract all annity purchases. Thus the equilibrium rate $\mathbb{A}$ is characterized by $\pi^{\prime}(\AA) \leq 0$. Henceforth, we assume that this inequality 
holds strictly.

12. See Appendir $C$ for conditions under which $\theta(p, A)<1$.

13. In Appendix $C$, we present condition $\$$ ander which $0<\bar{\theta}(A)<1$. These conditions guarantee that $B^{*}>0$ if $Y-T+A^{-1} S>0$ and will gaarantee that $B_{t}^{*}$ approaches the steady state $B^{*}$ monotonically.

14. It can also be shown that wth with logarithmic atility the introduction of actuarially fair social security leads to an increase in the amount of riskless bonds beld in the portfolios of young consumers. This result fallows from the fact that riskless bond holdings are proportional to $\frac{A}{A-R}(I+Y-T+A-1 S)$. (Substitutigg $(A-3 b)$ into $(A-5 b)$ in Appendix $A$ and then setting $\sigma$ equal to 1 yields $\theta^{-}=[1+\delta(1-p+\lambda)]^{-1} \delta_{\lambda R} \frac{A}{A-R}$.) Since the introdaction of social security leads to reduction in $A-R$ the factor $\frac{A}{A-R}$ rises. Te have already shown that the steady state expected present value of lifetime income rises with the introduction of social security. 
Abel, Andrew B. "Precautionary Savings and Accidental Bequests," American Economic Review, forthcoming (1985); previously circulated as National Burean of Economic Research Working Paper No. 1372.

Barro, Robert J. "Are Government Bonds Net Wealth?" Jonrnal of Political Economy, 82, 6 (November/December 1974), 1095-1117.

Barro, Robert J. and Friedman, James W., "On Uncertain Lifetimes," Jonrnal of Political Economy 85, 4 (Augnst 1977), 843-9.

Diamond, Peter, "National Debt in a Neoclassical Growth Mode1," American Economic Revie 55 (1965), 1126-50.

Drazen, Allan, "Government Debt, Human Capital and Bequests in a Life Cycle Mode 1," Journal of Political Economy 86, 3 (June 1978) 505-516.

Eckstein, Zvi, Eichenbaum, Martin S., and Peled, Dan, "The Distribution of Wealth and Welfare in the Presence of Incomplete Annity Markets," Qnar terly JonIna1 of Economics, forthcoming $1985 \mathrm{a}$.

and "Oncertain Lifetimes and the Welfare Enhancing Properties of Annuity Markets and Social Security, "Journal of Public Economics, forthcoming 1985 b.

Fischer, Stanley, "A Life Cycle Model of Life Insurance Purchases," International Economic Review, 14, 1 (February 1973), 132-152.

Hakansson, Nils H., "Optimal Consumption and Investment Strategies Under Risk, An Uncertain Lifetime, and Insurance," International Economic Review $X$ (October 1969).

Xarni, Edi and Zilcha, Itzhak, "A Welfare Analysis of Steady States in an Overlapping Generations Model with Uncertain Lifetime," Johns Hopkins University. Working Papers in Economics No. 137, April 1984.

Kotlikoff, Lanrence J., Shoven, John B., and Spivak, Avia, "Annuity Markets, Saving, and the Capital Stock," mimeo, NBER, September 1983 . 
Kotlikoff, Laurence J. and Spivak, Avia, "The Family as an Incomplete Annuities Market," Journal of Political Economy 89, 2 (Apri1 1981), 372-391.

Levhari, David and Mirman, Leonard, "Savings and Consmption with an Uncertain Horizon," Journal of Political Economy 85, 2 (April 1977), 265-281.

Modigliani, Franco and Brumberg, Richard, "Utility Analysis and Aggregate Consumption Functions: An Attempt at Integration," mimeo 1954.

Richard, Scott F., "Optimal Consumption, Portfolio and Life Insurance Rules for an Uncertain Lived Individual in a Continuous Time Mode1," Journal of Financial Economics, 2 (1975).

Rothschild, Michael and Stiglitz, Joseph, "Equilibrim in Competitive Insurance Markets: An Essay on the Economics of Imperfect Information," The Quarter1y Journal of Economics, 90 (November 1976), 629-649.

Samuelson. Paul A. "An Exact Consumption-Loan Model of Interest with or without the Social Contrivance of Money," Journal of Political Economy. 66,6 (December 1958), 467-82.

Sheshinski, Eytan and Weiss, Yoram, "Uncertainty and Optimal Social Security. Systems," The Quarterly Journal of Economics, 96, 2 (May 1981), 189-206.

Yaari, Menahem E., "Uncertain Lifetime, Life Insurance, and the Theory of the Consumer," Review of Economic Studies 32 (April 1965), 137-150. 


\section{Appendix $\underline{A}$}

In this Appendix we calcalate the optimal values of $c_{1}, c_{2}, B^{D}$ and $B^{S}$ for the case in which $\sigma()$ and $V()$ each have constant relative risk aversion equa 1 to $\sigma$. Because $\sigma^{\prime}(c)=c^{-\sigma}$ and $V^{\prime}(B)=\lambda B^{-\sigma}$, the first-order conditions (6ac) nay be rewitten as

$$
\begin{gathered}
c_{1}=[(1-p) \delta \lambda A]^{-\frac{1}{\sigma_{B}} S} \\
c_{2}=\lambda^{-\frac{1}{\sigma_{B}} S} \\
B^{D}=\left[\frac{1-p}{p}\left(\frac{A-R}{R}\right)\right]^{-\frac{1}{\sigma_{B}} S}
\end{gathered}
$$

$(A-1 c)$

Substituting (A-1a-c) into the 1 ifetime budget constraint (5) yields

$$
\mathrm{B}^{\mathrm{S}}=\mathrm{A}(\mathrm{I}+\mathrm{Y}-\mathrm{T})+\mathrm{S}-\left\{\mathrm{A}[(1-\mathrm{p}) \delta \lambda \mathrm{A}]^{-\frac{1}{\sigma}}+\lambda^{\frac{-1}{\sigma}}+\left(\frac{1-\mathrm{p})}{\mathrm{p}}\right)^{-\frac{1}{\sigma}}\left(\frac{\mathrm{A}-\mathrm{R}}{\mathrm{R}}\right)^{1-\frac{1}{\sigma}}\right\} \mathrm{B}^{\mathrm{S}}
$$

Re-writing (A-2), we obtain

$$
B^{S}=\theta^{S}(p, A)\left(I+Y-T+A^{-1} S\right)
$$

where

$$
\theta^{S}(p, A)=A\left[1+\lambda^{-\frac{1}{\sigma}}+[(1-p) \delta \lambda]^{-\frac{1}{\sigma}}{ }_{A}^{1-\frac{1}{\sigma}}+\left(\frac{1-p}{p}\right)^{-\frac{1}{\sigma}}\left(\frac{A-R}{R}\right){ }^{1-\frac{1}{\sigma}}\right]^{-1}
$$

Substituting $(A-3)$ into $(A-1 a)$ and simplifying gields

$$
c_{1}=\phi(p, A)\left(I+Y-T+A^{-1} S\right)
$$

where

$$
\phi(p, A)=\left\{1+\delta^{\frac{1}{\sigma}} A^{\frac{1}{\sigma}-1}\left[(1-p)^{\frac{1}{\sigma}}\left(1+\lambda^{\frac{1}{\sigma}}\right)+p^{\frac{1}{\sigma}} \lambda^{\frac{1}{\sigma}}\left(\frac{A-R}{R}\right)^{1-\frac{1}{\sigma}}\right]\right\}^{-1}
$$


To obtain en expression for $B^{D}$, substitute $(A 3-a)$ into $(A-1 c)$ which yie1ds

$$
B^{D}=\theta^{D}(p, A)\left(I+Y-T+A^{-1} S\right)
$$

where

$$
\theta^{D}(p, A)=\left(\frac{1-p)}{p}\right)^{-\frac{1}{\sigma}}\left(\frac{A-R}{R}\right)-\frac{1}{\sigma} S(p, A)
$$

The average bequest left by a type $p$ consumer, $B^{*}(p)$, is equal to $\mathrm{pB}^{D}+(1-\mathrm{p}) \mathrm{B}^{\mathrm{S}}$. Therefore, from $(\mathrm{A}-3)$ and $(\mathrm{A}-5)$ it follows that

$$
B^{*}(p)=\theta(p, A)\left(I+Y-T+A^{-1} S\right)
$$

where

$$
\theta(p, A)=\left[1-p+p\left(\frac{1-p}{p}\right)^{\frac{-1}{\sigma}}\left(\frac{A-R}{R}\right)^{\frac{-1}{\sigma}}\right] S_{(p, A)}
$$

Finally we calculate the demand for private annities by substituting $(A-1 b)$ and $(A-1 c)$ into (4) to obtain

$$
Q(p, A)+A^{-1} S=\left(1+\lambda^{-\frac{1}{\sigma}}-\left(\frac{1-p}{p}\right)^{\frac{-1}{\sigma}}\left(\frac{A-R}{R}\right)^{-\frac{1}{\sigma}}\right) A^{-1} B^{S}
$$

Substituting $(A-3 a, b)$ into $(A-7)$ yields

$$
Q(p, A)+A^{-1} S=q_{1}(p, A)\left(I+Y-T+A^{-1} S\right)
$$

where

$$
q_{1}(p, A)=\frac{1+\lambda^{\frac{1}{\sigma}}\left[1-\left(\frac{1-p)}{p}\right)^{-\frac{1}{\sigma}}\left(\frac{A-R}{R}\right)^{-\frac{1}{\sigma}}\right]}{1+\delta^{-\frac{1}{\sigma}}(1-p)^{-\frac{1}{\sigma}}{ }_{A}^{1-\frac{1}{\sigma}}+\lambda^{\frac{1}{\sigma}}\left[1+\left(\frac{1-p)}{p}\right)^{-\frac{1}{\sigma}}\left(\frac{A-R}{R}\right)^{1-\frac{1}{\sigma}}\right]}
$$




\section{Appendix B}

In this Appendix we show that under logarithmic atility, ( $\sigma=1)$, and with $I+Y-T>0$ and $S \geq 0, \pi(A)$ is strictly concave for $A>R$.

First we differentiate (14) twice with respect to A to obtain

$$
\pi^{\prime \prime}(A)=\int_{p^{L}}^{p^{B}}\left[\frac{\partial^{2} M}{\partial A^{2}} Q^{*}+2 \frac{\partial M}{\partial A} \frac{\partial Q^{*}}{\partial A}+\frac{\partial^{2} Q^{*}}{\partial A^{2}} M\right] d H(p)
$$

From (13), it follow that

$$
\begin{gathered}
\frac{\partial M}{\partial A}=-(1-p) \\
\frac{\partial^{2} M}{\partial A^{2}}=0
\end{gathered}
$$

Setting $\sigma=1$ in $(A-8 b)$ and differentiating with respect to A yields

$$
\frac{\partial q_{1}}{\partial A}=\frac{p \delta \lambda R}{(A-R)^{2}} b(p)>0
$$

Differentiating ( $10 b$ ) with respect to $A$ and nsing (B4) we obtain

$$
\frac{\partial q_{2}}{\partial A}=-b(p)\left[A^{-2}+\frac{p \delta \lambda}{(A-R)^{2}}\right]
$$

It follows from ( $B 4$ ) and (BS) that

$$
\frac{\partial Q}{\partial A}=\frac{p \delta \lambda R}{(A-R)^{2}} b(p)(I+Y-T)+\phi(p)\left[A^{-2}+\frac{p \delta \lambda}{(A-R)^{2}}\right] \dot{S}
$$

Differentiating (B6) with respect to A yields

$$
\frac{\partial^{2} Q}{\partial A^{2}}=\frac{-2 p \delta \lambda R}{(A-R)^{3}} b(p)(I+Y-T)-2 \phi(p)\left[A^{-3}+\frac{D \delta \lambda}{(A-R)^{3}}\right] S
$$

Substituting (13), (B2), (B3), (B6), and (B7) into (B1) yie1ds

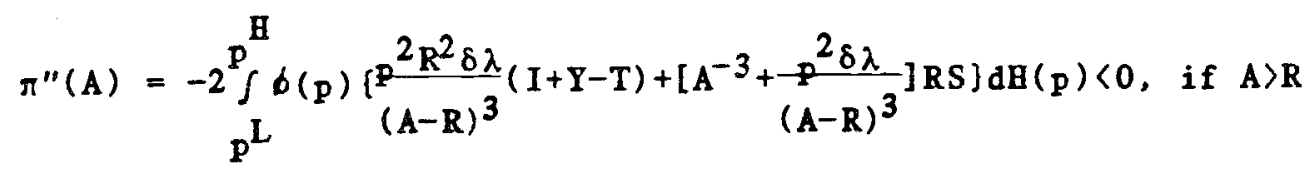




\section{Appendix C}

In this Appendix we restrict our attention to the case of logarithmic utility $(\sigma=1)$ and derive conditions under which $\bar{\theta}<\bar{\sigma}$ and conditions under which $\bar{\delta} \leq \bar{\theta}<1$. We begin by defining the function $\gamma(p, q)$ as

$$
\gamma(p, q) \equiv \lambda\left[\frac{p^{2}}{q}+\frac{(1-p)^{2}}{(1-q)}\right]
$$

Now define $p^{*}\left(p^{L} \leq p^{*} \leq p^{B}\right)$ as the probability of dying young which is implicit in the rate of return on private annuties, i.e.,

$$
\mathbf{R}=(1-\mathbf{p}) \mathbf{A}
$$

From the definition of $\theta(p, A)$ in $(A-6 b)$ and using $(A-3 b)$ and $(A-4 b)$ it can be shown that with logarithmic atility ( $\sigma=1)$

$$
\theta(p, A)=b(p) \delta \lambda A\left[(1-p)^{2}+p^{2} \frac{R}{A-R}\right]
$$

Then using (C1) and (C2), we may rewrite (C3) as

$$
\theta(p, A)=b(p) \delta R \gamma\left(p, p^{*}\right)
$$

Differentiating $\gamma(p, q)$ twice ith respect to $p$ and $q$ demonstrates that $\gamma(p, q)$ is strictly conver in $p$ and in $q$ so that

$$
\begin{aligned}
& \sup _{p^{L} \leq p^{H}} \gamma(p, q)=\max \left[\gamma\left(p^{L}, q\right), \gamma\left(p^{H}, q\right)\right] \\
& \text { sup }_{p^{L} \leq q \leq p^{H}} \gamma(p, q)=\max \left[\gamma\left(p, p^{L}\right), \gamma\left(p, p^{H}\right)\right]
\end{aligned}
$$

It can al so be shown that

$$
\mathrm{p}^{\mathrm{L} \leq \mathrm{p}, \mathrm{q} \leq \mathrm{p}^{\mathrm{H}}}{ }^{\gamma(\mathrm{p}, \mathrm{q})=\gamma(p, p)=\lambda}
$$

Combining (C5), (C6) and (C7), we obtain 


$$
\lambda \leq \gamma(p, q) \leq \max \left[\gamma\left(p^{L}, p^{H}\right), \gamma\left(p^{H}, p^{L}\right)\right] \quad \text { for } p^{L} \leq p, q<p^{H}
$$

Note that for a given $p^{L} \quad\left(\right.$ or $\left.p^{H}\right), \gamma\left(p^{L}, p^{H}\right)$ and $\gamma\left(p^{H}, p^{L}\right)$ are maximized by maximizing $\mathrm{p}^{\mathrm{H}}$ (or minimizing $\mathrm{p}^{\mathrm{L}}$ ). Recall, however, that we have restricted the values of $\mathrm{p}^{\mathrm{L}}$ and $\mathrm{p}^{\mathrm{H}}$ in (12) in order to assure positive demands for annities by all consumers. Setting $p^{L}$ equal to its lower bound $\frac{\lambda_{p}{ }_{1}}{1-p^{H}+\lambda}$ yields

$$
\gamma\left(\mathrm{p}^{\mathrm{H}}, \mathrm{p}^{\mathrm{L}}\right) \leq \frac{1}{1+\lambda}\left(1-\mathrm{p}^{\mathrm{H}}+\lambda\right)\left(\lambda+\mathrm{p}^{\mathrm{H}}\right)
$$

Similarly, setting $p^{H}=\frac{1+\lambda}{p^{L}+\lambda} p^{L}$, we obtain

$$
\gamma\left(p^{L}, p^{H}\right) \leq \frac{1}{1+\lambda}\left(1-p^{L}+\lambda\right)\left(\lambda+p^{L}\right)
$$

Fram (C9) and (C10), it follows that

$$
\gamma(p, q) \leq \frac{1}{1+\lambda}\left[\lambda+\lambda^{2}+\max \left(p^{H}-p^{H^{2}}, p^{L}-p^{L^{2}}\right)\right]
$$

From (C11) it follows that

$$
\begin{array}{cl}
\gamma(\mathrm{p}, \mathrm{q})<1 & \text { if } \lambda<\mathrm{p}^{\mathrm{L}}<\mathrm{p}^{\mathrm{H}} \\
\text { or if } \lambda^{2}<\frac{3}{4}
\end{array}
$$

Thus from (C4) and (C12), and recalling the definitions of $\bar{\theta}$ and $\bar{b}$, we have

$$
\bar{\theta}<\bar{\delta} \text { if } \delta R \leq 1 \text { and if } \lambda<\max \left[p^{L},(3 / 4)^{1 / 2}\right]
$$

Next we establish conditions under which $\bar{\phi}<\bar{\theta}<1$. It follows immediately from (C4) that

$$
\theta(p, A) \leq \delta B \sup _{p^{L} \leq p \leq p} \phi(p) \sup _{p^{L} \leq p, q \leq p^{H}} \gamma(p, q)
$$

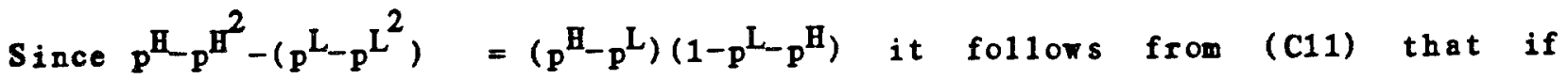
$\mathbf{p}^{\mathrm{L}}+\mathbf{p}^{\mathrm{H}} \leq 1$, then 


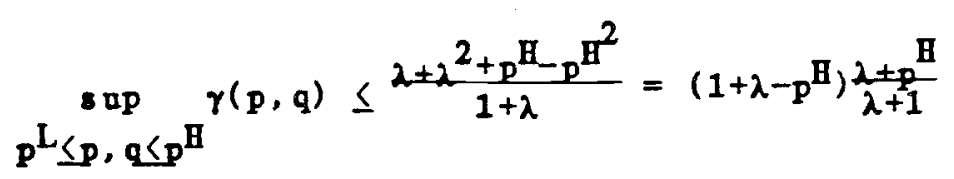

Using the definition of $\phi(p),(C 15)$ may be rewitten as

$$
p^{L} \leq p, q<p^{B} \gamma(p, q) \leq \delta^{-1}\left(\frac{1}{\delta\left(p^{H}\right)}-1\right) \frac{\lambda+p}{\lambda+1} \text {, if } p^{L_{+}} p^{B} \leq 1 \text {. }
$$

Dsing (C16) and the fact that sup $\phi(p)=\phi\left(p^{H}\right),($ c14) yields

$$
\begin{gathered}
p^{L} \leq p \leq p^{B} \\
\theta(p, A) \leq R\left(1-\phi\left(p^{B}\right)\right) \frac{\lambda+p^{B}}{\lambda+1}<R \text {, if } p^{L}+p^{B} \leq 1
\end{gathered}
$$

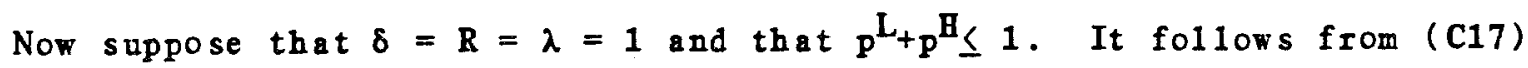
that $\theta(p, A)<1$ and hence $\bar{\theta}<1$. It follows from (CA) and (C8) that $\theta(p, A) \geq \phi(p)$ with strict inequality for $p \neq p *$. Therefore $\bar{\theta}>\bar{\phi}$ so that we have established the existence of parameter values for which $\bar{\delta}<\bar{\theta}<1$. 


\section{Appendix D}

In this Appendix, we show that with logarithmic atility $(\sigma=1), \sigma^{\prime}(A) \leq 0$ if $S=0$. It follows from the definition of $\bar{\theta}(\mathrm{A})$ in (20b) that

$$
\bar{\theta}(A)=\int_{p^{L}}^{\mathbf{p}} \frac{\partial \theta(p, A)}{\partial A} d H(p)
$$

Differentiating (C3) with respect to A yields

$$
\frac{\partial \theta(p, A)}{\partial A}=-b(p) \delta \lambda[p R+(1-p)(A-R)] \frac{M(p, A)}{(A-R)^{2}}
$$

Substituting (D1) into (D2) yields

$$
\bar{\theta}^{\prime}(A)=-\int_{p^{L}}^{p} f(p) g(p) d B(p)<0 \text { if } S=0
$$

where

$$
\begin{aligned}
f(p) & =\frac{\lambda}{(A-R)^{2}} M(p, A) Q(p, A) \\
g(p) & =\frac{[D R+(1-p)(A-R)]_{\delta}}{Q(p, A)] \delta(p)}
\end{aligned}
$$

The inequality in (D3a) follows immediately from the Lemma after observing that $\int_{p^{L}}^{p} f(p) d H(p)=\frac{\lambda}{(A-R)^{2}} \pi(A)=0$ and showing that $g^{\prime}(p) \geq 0$. Below, we show that if $S=0$, then $g^{\prime}(p)>0$.

Using (10a), (A4b) and (A8b) we find that with logarithmic atility and $S=0$

$$
\frac{\partial(Q / Q)}{\partial p}=-\delta\left(1+\lambda \frac{A}{A-R}\right)(I+Y-T)
$$

Differentiating (D3c) with respect to p and asing (D4) yields

$$
B^{\prime}(P)=\frac{1}{[Q(P, A) / \phi(p)]^{2}}\left[\delta^{2}(1+2 \lambda) R(I+Y-T)\right]>0
$$

